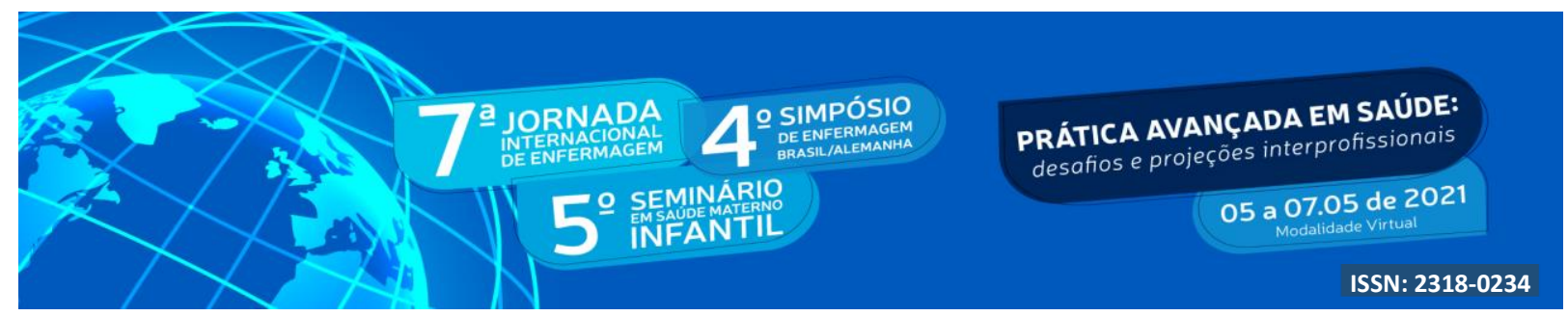

DOI: http://doi.org/10.48195/jie2021-156

\title{
FORMAÇÃO EMPREENDEDORA NA ENFERMAGEM: REVISÃO INTEGRATIVA ${ }^{1}$
}

\section{Giulia Dos Santos Goulart ${ }^{2}$; Glória $\operatorname{Cogo}^{3}$; Gabriéli da Silva ${ }^{4}$; Carla Ferreira ${ }^{5}$; Dirce Stein Backes ${ }^{6}$; Lenise Dutra da Silva ${ }^{7}$}

\begin{abstract}
RESUMO
Este estudo teve como objetivo analisar as produções científicas relacionadas à formação empreendedora na enfermagem. Trata-se de um estudo de revisão integrativa, cujos periódicos foram consultados no mês de março de 2021. A abordagem do empreendedorismo nos Cursos de Enfermagem tem contribuído para que a profissão ganhe novos espaços no mercado de trabalho e que os profissionais explorem as oportunidades. As oportunidades de empreendimento são variadas e podem estar ligadas tanto aos negócios ou estarem atreladas ao empreendedorismo social. Observou-se, com este estudo, que a abordagem do empreendedorismo nos Cursos de Enfermagem é relevante para que a profissão ganhe novos espaços no mercado de trabalho e que os profissionais explorem as oportunidades. Ainda, percebeu-se que existem alguns desafios para o desenvolvimento do perfil empreendedor entre os acadêmicos de enfermagem.
\end{abstract}

Palavras-chave: Enfermagem; Empreendedorismo; Formação Acadêmica.

\begin{abstract}
This study aimed to analyze how scientific productions related to entrepreneurial training in nursing. This is an integrative review study, journals were consulted in March 2021. The approach to entrepreneurship in Nursing Courses has contributed to the profession gaining new spaces in the job market and for professionals to explore as opportunities. Entrepreneurial opportunities are varied and can be linked to business or linked to social entrepreneurship. It was observed, with this study, that the approach of entrepreneurship in Nursing Courses is relevant for a profession to gain new spaces in the job market and for professionals to explore opportunities. Still, it is certain that there are some challenges for the development of the entrepreneurial profile among nursing students.
\end{abstract}

Key Words: Nursing; Entrepreneurship; Academic Formation.

\footnotetext{
${ }^{1}$ Tipo de trabalho: Revisão Integrativa.

2 Acadêmica de Enfermagem. URI-Câmpus de Santiago. E-mail: giuliagoulart@outlook.com

3 Acadêmica de Enfermagem. URI-Câmpus de Santiago. E-mail: gloriabio1@gmail.com

${ }^{4}$ Acadêmica de Enfermagem. URI-Câmpus de Santiago. E-mail: gabrielironzani.gr@gmail.com

${ }^{5}$ Enfermeira. Doutora em Enfermagem. Coordenadora do Curso de Enfermagem. Universidade Franciscana. Email: carlalizandralferreira@gmail.com

${ }^{6}$ Doutora em Enfermagem. Coordenadora do Mestra Profissional em Saúde Materno Infantil. Universidade Franciscana. E-mail: backes.dirce@ufn.edu.br

${ }^{7}$ Enfermeira. Mestre em Saúde Materno Infantil. Docente do Curso de Enfermagem da URI-Câmpus de Santiago E-mail: enfermeira.lenise@gmail.com
} 


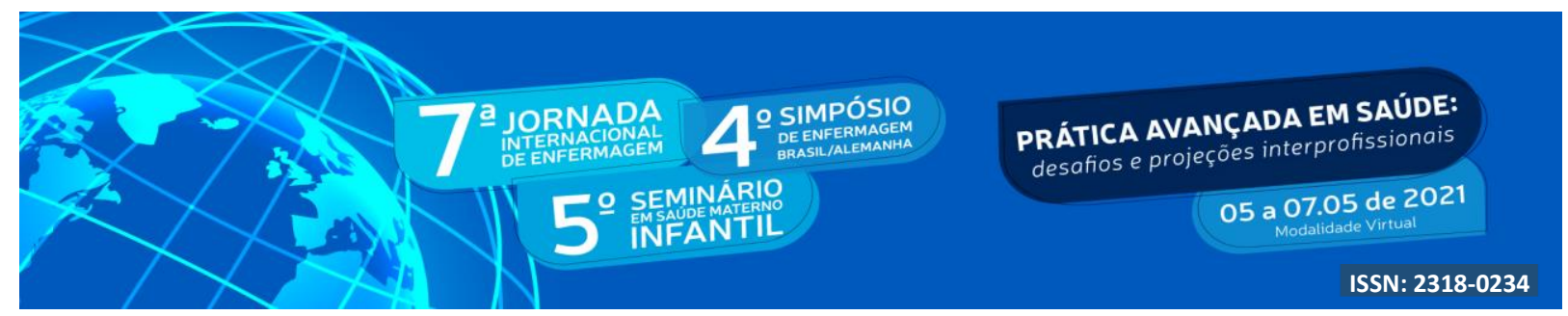

\section{INTRODUÇÃO}

Entre os países emergentes, o empreendedorismo se destaca como uma grande abordagem geradora de impacto socioeconômico. O mesmo é visto como uma ferramenta criativa, inovadora e comprometidas com as questões sociais e de saúde da população, sendo incorporado nos planos e programas de políticas públicas. Ainda, tem papel essencial na diminuição da taxa de desemprego (SANCHEZ; GUERRERO; CUBILLOS, 2020).

Dentre as novas abordagens de intervenção o empreendedorismo se destaca, a partir de uma compreensão sistêmica da realidade, capaz de mobilizar recursos e competências na direção de soluções criativas, inovadoras e comprometidas com as questões sociais e de saúde da população (BACKES et. al., 2016a).

No Brasil, o empreendedorismo se disseminou a partir dos anos 90, com a criação de políticas que apoiavam e estimulavam a abertura de micro e pequenas empresas. $\mathrm{Na}$ enfermagem, a visão empreendedora não se resume, somente, aos ganhos capitais, mas associa-se à criação de conteúdo ou aprimoramento do mesmo, enfatizando a necessidade de busca pela possibilidade de estar por dentro das novas formas de promoção prevenção e educação em saúde (BACKES et. al., 2016b).

A oportunidades de empreender na enfermagem são inúmeras, mas ainda pouco exploradas. Acredita-se que isso ocorra devido ao sistema de saúde, que absorve a maior parte dos profissionais de enfermagem em instituições hospitalares, diferente do que acontece nas outras profissões como psicologia, fisioterapia, terapia ocupacional, odontologia. Ademais, os enfermeiros buscam pela segurança financeira recorrendo a concursos públicos. Então, já que o empreendimento é caracterizado por ser um risco financeiro, acaba por não tornar-se a primeira opção (COLICHI; LIMA, 2018).

Nesse sentido, acredita-se que essa realidade possa ser transformada a partir da inserção de disciplinas de empreendedorismo nos cursos de graduação e pós-graduação, ou seja, instigar nos estudantes o desejo de empreender. Proporcionar que estudantes tenham experiência educacional durante a formação preparará os acadêmicos para o novo mercado de trabalho (COLICHI et al., 2020). 


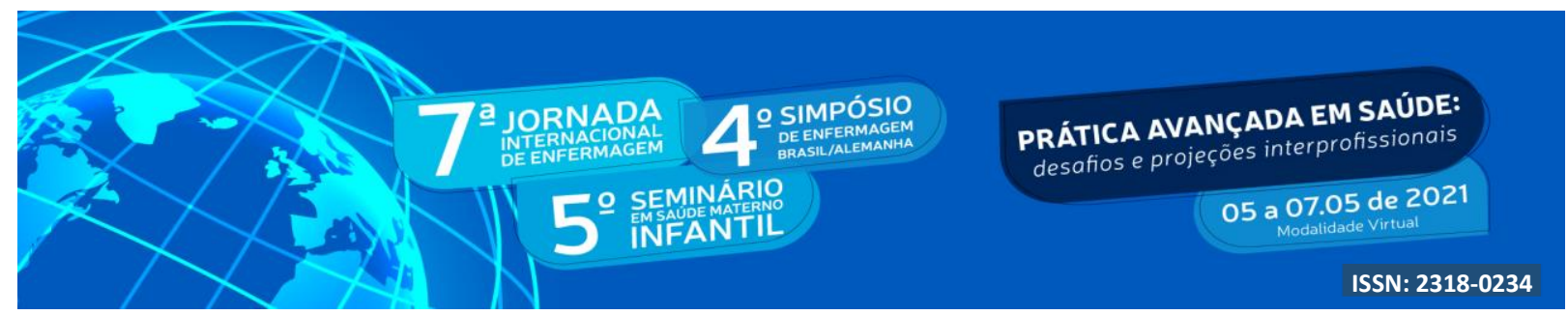

Com base nessas considerações e na tentativa de conhecer o que já foi produzido sobre empreendedorismo na formação da enfermagem em âmbito nacional e internacional, questiona-se: Como está sendo abordado o empreendedorismo na formação da enfermagem?

\section{OBJETIVO}

Analisar as produções científicas relacionadas à formação empreendedora na enfermagem.

\section{METODOLOGIA}

Trata-se de um estudo de revisão integrativa, cujos periódicos foram consultados no mês de março de 2021. A revisão integrativa foi construída a partir da análise e interpretações de produções e estudos já existentes, formando assim conceitos e definições substanciais (WHITTEMORE; KNALF, 2005; GANONG, 1987).

A sistematização desta revisão integrativa se deu em seis etapas. A primeira etapa constituiu da formulação da questão pesquisa "Como está sendo abordado o empreendedorismo na formação de enfermeiros?". Para responder esta questão pesquisa realizaram-se buscas nas bases de dados BDEnf, Medline, Lilacs, PubMed. Na segunda etapa foram definidos como critérios de inclusão: artigos disponíveis na íntegra nos últimos 5 anos, em idiomas português, inglês e espanhol, publicados e indexados nas referidas bases de dados e sem limite temporal. Como critérios de exclusão: artigos completos não gratuitos, dissertações e teses. Artigos duplicados foram considerados apenas uma vez (WHITTEMORE; KNAFL, 2005).

A terceira e quarta etapas se constituíram da busca na base a partir das palavras-chave e dos descritores "Empreendedorismo" and "Enfermagem" and "Ensino" e mesh "Entrepreneurship" and "Nursing" and "Education". Nestas etapas foram encontrados 32 artigos, dos quais realizou-se a leitura dos títulos e resumos e, na sequência, a leitura na íntegra dos artigos que apresentavam conteúdo concernente ao objetivo proposto. Ao final deste processo, o corpus deste estudo resultou em sete artigos. Posteriormente, se criou um fluxograma com o detalhamento das etapas de pesquisa (Figura 1) e uma tabela contendo a síntese nos artigos selecionados e o nível de evidência científica (Quadro 1). Já, na quinta 


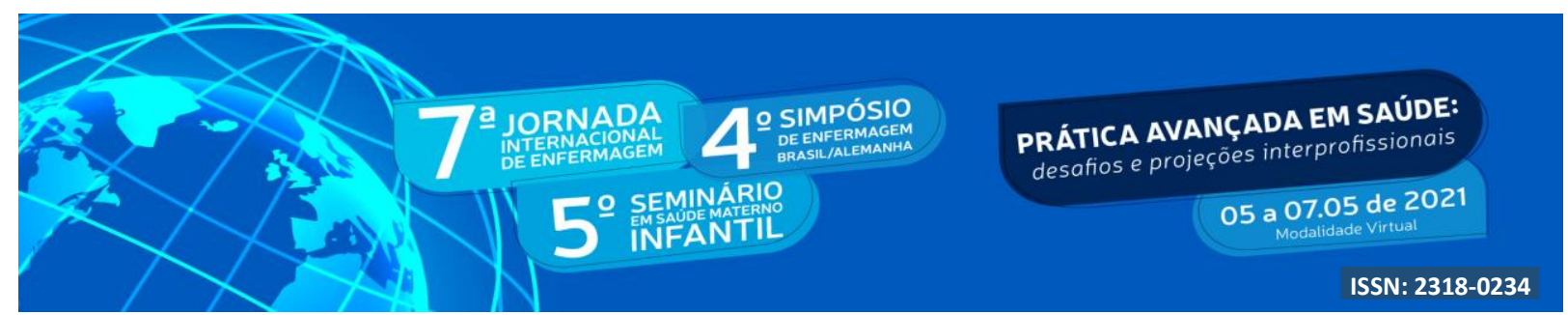

etapa, realizou-se a discussão dos resultados; e, na sexta etapa, delinearam-se as considerações finais, com a análise dos vieses.

Figura 1 - Fluxograma com o detalhamento da pesquisa

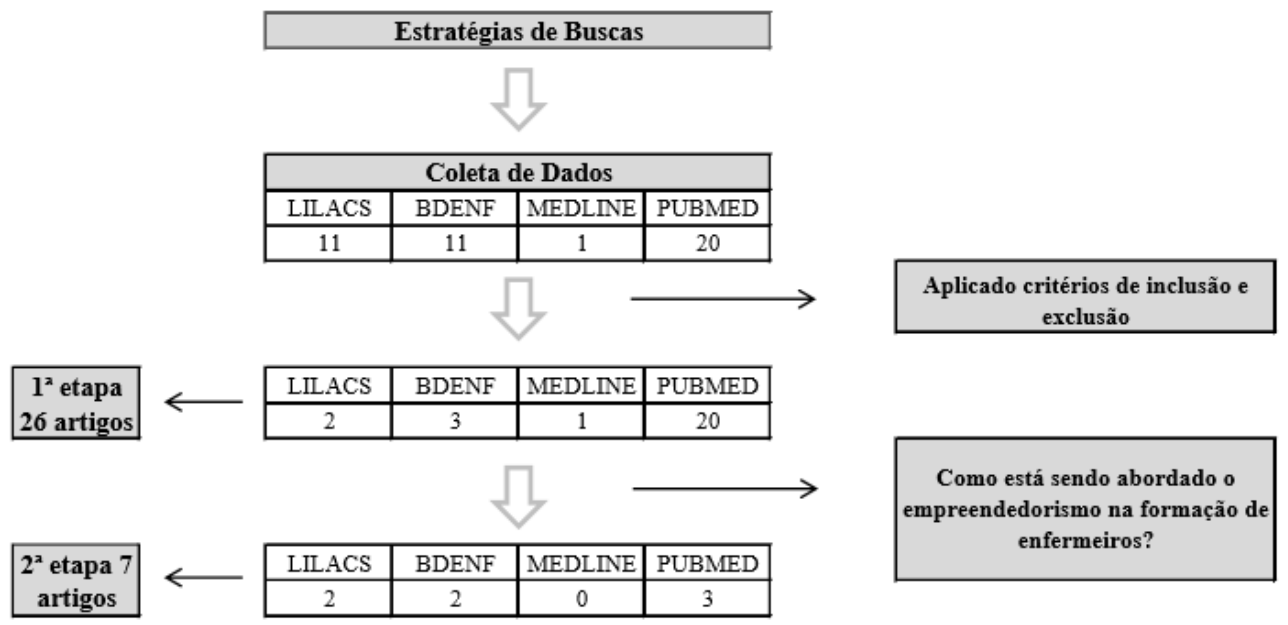

FONTE: Elaborado pelas autoras.

\section{RESULTADOS E DISCUSSÃO}

\section{Descrição dos estudos}

A evolução temporal dos artigos selecionados demonstrou que os mesmos foram publicados entre os anos de 2016 e 2021, ocorrendo gradativamente. Os sete artigos analisados foram publicados em periódicos diferentes. Nenhum periódico apresentou mais de uma publicação.

Em relação aos países de publicação dos artigos, houve cinco artigos $(71,42 \%)$ no Brasil, um no Irã $(14,28 \%)$ e um nos Estados Unidos (14,28\%). Cinco artigos $(71,42 \%)$ artigos estudados tiveram abordagem metodológica qualitativa. No que tange ao desenho do estudo, três eram descritivo-exploratórios e o restante apresentaram outros tipos de desenhos metodológicos.

Quanto ao contexto abordado nos estudos, três estiveram relacionados ao empreendedorismo social; um, ao empreendedorismo de negócios; e um, ao empreendedorismo com percepção ampliada. 


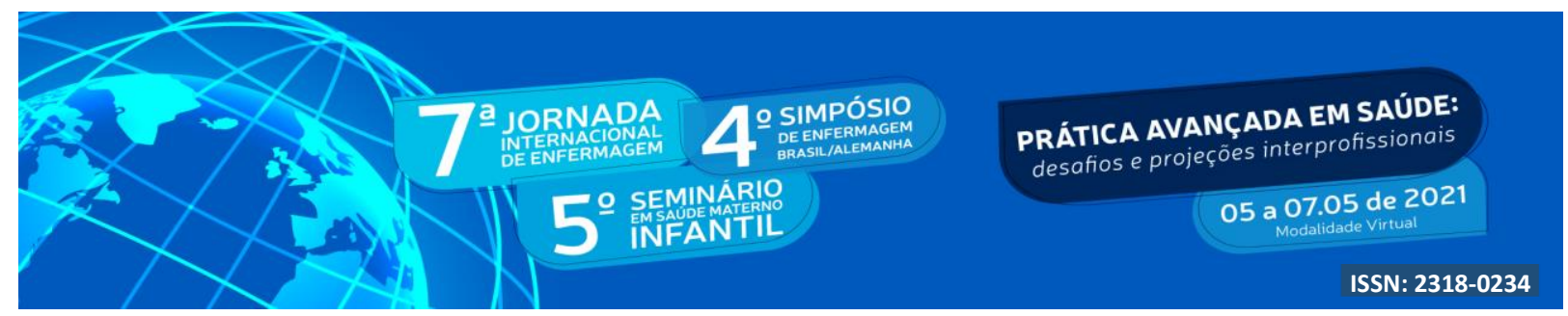

Após a análise dos dados emergiram as seguintes categorias: A formação do enfermeiro para o empreendedorismo; e Dificuldades encontradas ao empreender na saúde.

\section{A formação do Enfermeiro para o Empreendedorismo}

A formação tradicional que, por várias décadas, direcionou o futuro enfermeiro a buscar emprego em instituições já existente, teve o seu foco central na formação de bons empregados. Nessa direção, o profissional saia das escolas e universidades com uma percepção reducionista da sua prática, e não com foco na construção do seu empreendimento, exercitando sua criatividade, capacidade de administração e de negociar (SANTOS; BOLINA, 2020).

A superação desse modelo é questionada com a inserção de disciplinas e atividades que integram o empreendedorismo nos Cursos de Graduação em Enfermagem em universidades nacionais e internacionais. Copelli et al. (2017) identifica que o ensino do empreendedorismo, durante a formação profissional, fortalece a capacidade empreendedora dos acadêmicos. No entanto, não basta abordar a temática do empreendedorismo, mas é preciso criar espaços de vivências empreendedoras e afirmativas destas possibilidades, pois a demanda por educação empreendedora e a autoeficácia empreendedora é fator confirmado para que o aumento do interesse em empreender surja nos acadêmicos de enfermagem (LIM; KIM; KIM, 2021).

O pensamento crítico-reflexivo pode/deve ser incorporado nos primeiros semestres do curso, permitindo que o acadêmico se insira na comunidade e perceba as oportunidades de empreender e de transformar aquela realidade. Ainda, durante a graduação podem ser abordadas questões éticos-legais, para que o futuro profissional conheça as possibilidades empreendedoras existentes na enfermagem. A saber, em 2018 o Conselho Federal de Enfermagem (COFEN) regulamentou por meio da Resolução $n^{\circ}$. 0568/2018 o funcionamento de consultórios e clínicas de enfermagem, valorizando o caráter empreendedor dos enfermeiros (SANTOS; BOLINA, 2020).

A formação para o empreendedorismo não se restringe somente ao de negócio, mas também ao empreendedorismo social, que busca induzir os profissionais a se tornarem agentes ativos e transformadores das suas práticas nos mais diversos cenários de atuação. Os 


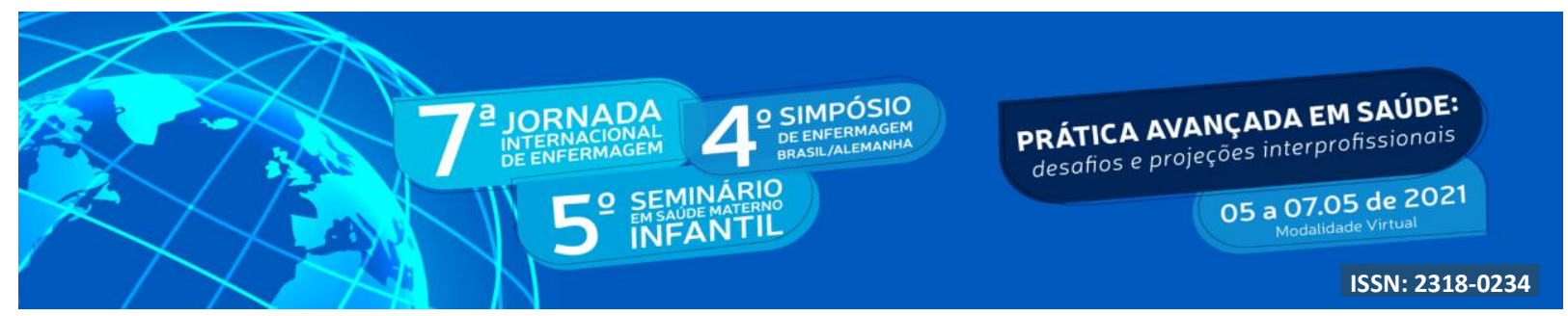

enfermeiros que tiveram essa formação promissora estarão abertos e flexíveis a qualquer adversidade e verão nela uma oportunidade de fazerem diferente e, assim, exercerem o protagonismo social (BACKES; ERDEMANN, 2009; GILMARTIN, 2013; SANTOS; BOLINA, 2020).

A criatividade e a inovação são essenciais para o cuidado em saúde. Essas habilidades empreendedoras, na enfermagem, contribuem para o desenvolvimento econômico de um país através da geração de novos empregos, na transformação de cenários e na superação de práticas assistenciais que contribuem para a acomodação dos usuários de saúde (BOORE; PORTER, 2011).

O campo de atuação da enfermagem proporciona grande oportunidade para que os profissionais empreendam em negócios ou em ações de promoção da saúde. Nesse sentido, é indispensável que as universidades proporcionem, ao acadêmico, vivencias teórico-práticas sobre empreendedorismo (COLICHI et. al., 2020). A inclusão de disciplinas de empreendedorismo, em várias universidades, já é uma realidade e se traduz em tendência para o alcance de resultados mais efetivos e transformadores. Portanto, é imprescindível que exista a divulgação e desmistificação do tema de forma correta, respeitando a cultura profissional e preparando futuros enfermeiros para o mercado de trabalho (COLICHI et al., 2020; SANTOS; BOLINA, 2020).

\section{Desafios para empreender na Enfermagem}

Segundo Colichi et al. (2020) e Copelli et al (2017) diversos são os motivos para que acadêmicos, docentes e enfermeiros não atuem avidamente no empreendedorismo e o percebam como negativo. Entre eles está o tempo demandado, condições de saúde e a sobrecarga horária de estudo/trabalho. Ainda, o desconhecimento acerca do empreender, a baixa autoestima e a falta de capacitação acerca do tema dificultam a atuação profissional. Assim, verifica-se que fatores pessoais influenciam diretamente na abertura de negócios na enfermagem

Para Chiavenato (2012), Hisrich, Peters e Shepherd (2014) empreendedor é caracterizado como aquele que percebe e aproveita as oportunidades, de (re) criar algo que antes ninguém imaginou. Além disso, ele é ousado para enfrentar os riscos e assumir as 


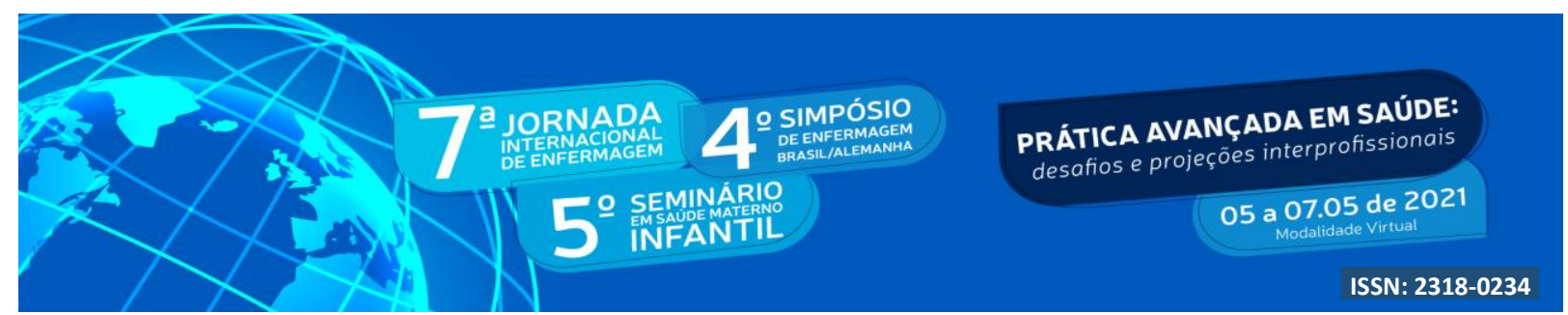

responsabilidades desse empreendimento, embora reconhecendo as incertezas e as adversidades a que se expõe. A Enfermagem é uma profissão com grande potencial empreendedor, pelo seu amplo campo de atuação, e que os profissionais possuem um perfil empreendedor e inovador, mas ainda precisa ser reconhecido por eles próprios e desenvolvido durante a formação acadêmica.

A crença histórica de que a enfermagem é uma prática de caridade, adiciona-se o fato de que gerar dinheiro a partir de um cuidado clínico pode trazer um conflito ético ou uma sensação de que lucrar a partir do seu trabalho/serviço é errado (COLICHI et al., 2020). Aliado a isso, a tradição de trabalho realizado em serviços públicos de saúde são ainda a primeira escolha de graduandos e profissionais recém formados, devido à estabilidade garantida pelo Estado, que no Brasil é quem detém maior responsabilidade pela saúde (COPELLI et. al., 2017).

Tendo em vista os receios dos profissionais acerca de questões éticas, sociais e financeiras, o ambiente para as necessidades diversas e vitais do empreendedorismo em enfermagem conseguirem se estabelecer precisa ser mais clara. Acredita-se que assim, será possível que surja nos acadêmicos de enfermagem interesses pelo empreendedorismo durante a faculdade e/ou carreira futura (LIM; KIM; KIM, 2021).

Ainda, as instituições de ensino exercem papel fundamental ao instigarem o acadêmico a pensar de forma criativa, inovadora e transformadora. As incubadoras tecnológicas e de aprendizagem são espaços oferecidos nas universidades e podem auxiliar o futuro profissional a desenvolver suas ideias empreendedoras, sejam elas voltadas para um cuidado diferenciado ou para uma tecnologia na saúde (BACKES et al., 2015).

\section{CONCLUSÃO}

Observou-se, com este estudo, que a abordagem do empreendedorismo nos Cursos de Enfermagem é relevante para que a profissão ganhe novos espaços no mercado de trabalho e que os profissionais explorem as oportunidades. Ainda, percebeu-se que existem alguns desafios para o desenvolvimento do perfil empreendedor entre os acadêmicos de enfermagem. E para isso, a formação para o empreendedorismo nas universidades, aliada a disponibilidade 


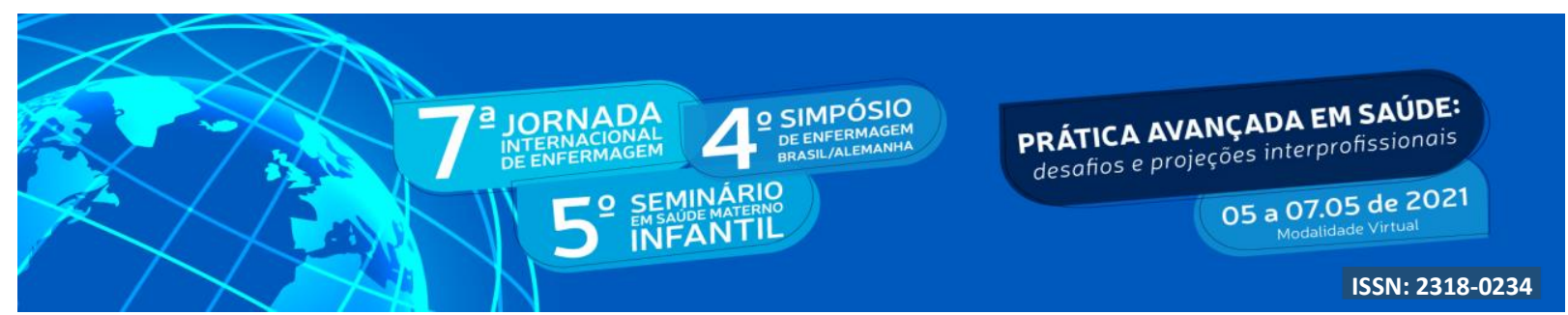

de espaços para o desenvolvimento das ideias, tecnologias e projetos empreendedores dos acadêmicos e profissionais são fundamentais para que os futuros enfermeiros saiam mais preparados.

As oportunidades de empreendimento são variadas e podem estar ligadas tanto aos negócios como, por exemplo, à abertura de uma home care, consultoria, tecnologias para a saúde ou estarem atreladas ao empreendedorismo social.

Considera-se como limitações deste estudo a escolha por apenas três idiomas e de artigos gratuitos. Sugere-se que sejam realizadas novas pesquisas na área com mais inclusões e que as universidades divulguem as atividades empreendedoras que estão sendo desenvolvidas. 


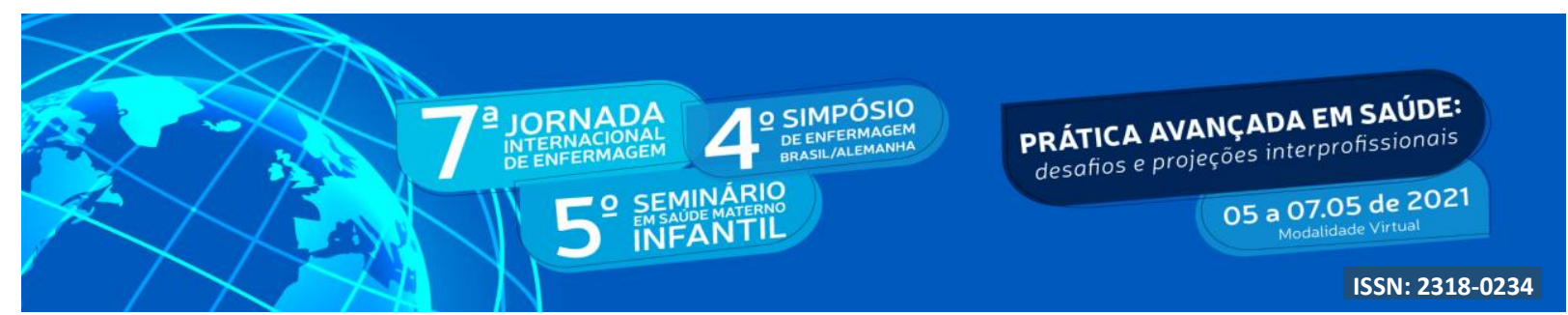

\section{RERÊNCIAS}

BACKES, D. S.; ERDMANN, A. L. Formação do enfermeiro pelo olhar do empreendedorismo social. Rev Gaúcha Enferm, v. 30, n. 2, p. 242-248, 2009.

BACKES, D. S. et al. Atividades socialmente empreendedoras na enfermagem: Contribuições à saúde/viver saudável. Esc Anna Nery, v. 20, n. 1, p. 77-82, 2016a.

BACKES, D. S. et al. Incubadora de Aprendizagem: ferramenta indutora do empreendedorismo na Enfermagem. Rev Bras Enferm, v. 68, n. 6, p. 1103-1108, 2015.

BACKES, D. S. et al. Interatividade sistêmica entre os conceitos interdependentes de cuidado de enfermagem. Aquichán, v. 16, n. 1, p. 24-31, 2016 b.

BOORE, J.; PORTER, S. Education for entrepreneurship in nursing. Nurse Education Today. v. 31, p. 184-191, 2011.

CHIAVENATO, I. Empreendedorismo: dando asas ao espírito empreendedor. 4. ed. Barueri, SP: Manole, 2012.

COLICHI, R. M. B. et al. Perfil e intenção empreendedora de estudantes de enfermagem: comparativo entre Brasil e Chile. REBEn, v. 73, n. 6, p. 1-9, 2020.

COLICHI, R. M. B.; LIMA, S. A. M. Empreendedorismo na enfermagem : comparação com outras profissões da saúde. Rev. Eletr. Enf, v. 20, n. 11, p. 1-11, 2018.

COPELLI, F. H. DA S. et al. Empreendedorismo na gestão universitária pública de enfermagem: entraves e estratégias. Rev RENE, v. 18, n. 5, p. 577-583, 2017.

GANONG, L. H. Integrative reviews of nursing research. Res Nurs Health. v. 10, n. 1, p. 1$11,1987$.

GILMARTIN, M. J. Principles and Practices of Social Entrepreneurship for Nursing. Journal of Nursing Education. v. 52, n. 11, p-641-644, 2013.

HISRICH, R. D.; PETERS, M. P.; SHEPHERD, D. A. Empreendedorismo. 9. ed. São Paulo: AMGH Editora Ltda, 2014.

LIM, J. Y.; KIM, G. M.; KIM, E. J. Predictors of Entrepreneurial Intention of Nursing Students Based on Theory of Planned Behavior. 2021.

SANCHEZ, M. R.; GUERRERO, J. P.; CUBILlOS, B. P. Caracterización y motivaciones para el emprendimiento femenino en MIPYMES de Villavicencio - Colombia. Tendencias, v.21, n.2, p. 146-166, 2020.

SANTOS, J. L. G. DOS;; BOLINA, A. F. Empreendedorismo na enfermagem: uma 


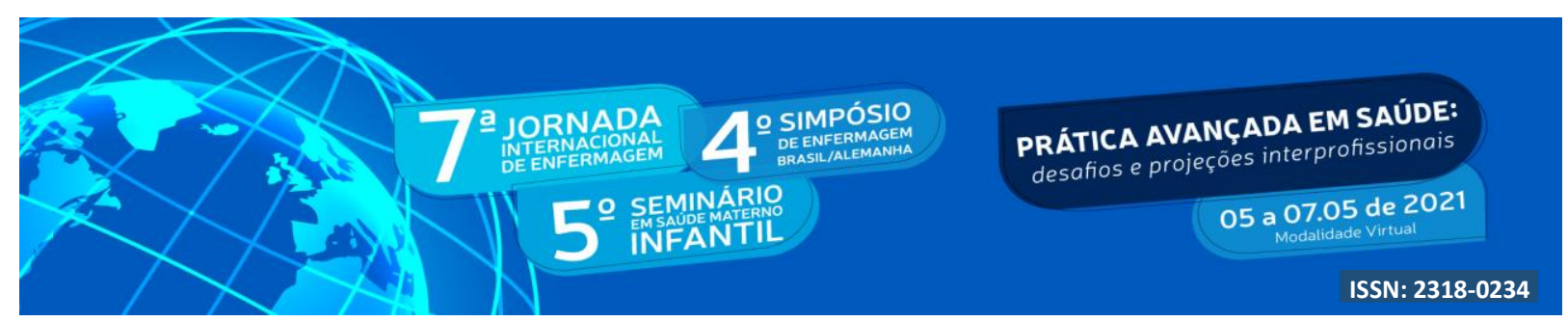

necessidade para inovações no cuidado em saúde e visibilidade profissional, 2020.

WHITTEMORE, R, KNAFL, K. The integrative review: update methodology. J Adv Nurs. v. 52 n. 5 p. 546-53, 2005. 